\title{
A indissociabilidade entre ensino, pesquisa e extensão: o caso do estágio de docência na pós-graduação
}

\section{The link between teaching, research and extension: the teaching practice of students in post-graduation}

\author{
Filomena Maria Gonçalves da Silva Cordeiro MOITA* \\ Fernando Cézar Bezerra de ANDRADE**
}

\begin{abstract}
RESUMO: Neste texto discutimos a indissociabilidade entre ensino, pesquisa e extensão como um princípio orientador da qualidade da produção universitária. Embora reconheçamos a importância de articulações duais, o que defendemos é um princípio que, se posto em prática, impede os reducionismos que se verificam na prática universitária. Com essa compreensão, enquanto doutorandos em educação, durante nosso estágio de docência realizamos um exercício da indissociabilidade. Ele é apresentado como uma experiência que buscou relacionar o conhecimento científico e o saber de educadores e educandos de uma escola, com vistas à produção de conhecimento acerca da articulação entre relações de gênero, violência e jogos eletrônicos. Defendemos duas idéias centrais: a primeira delas afirma que a indissociabilidade entre ensino, pesquisa e extensão ainda não é levada em conta na prática de muitos docentes, seja porque na graduação dá-se ênfase ao ensino, seja porque na pós-graduação a ênfase incide na pesquisa. A segunda idéia, decorrente da nossa experiência, consiste na afirmação de que o estágio de docência na pós-graduação é uma excelente oportunidade de praticar-se a indissociabilidade defendida. Com a apresentação de nossa experiência, pretendemos demonstrar esse argumento.
\end{abstract}

Palavras-chave: indissociabilidade entre ensino, pesquisa e extensão, pós-graduação, estágio de docência

\footnotetext{
* Mestre em Educação pela UFPB. Professora da Universidade Estadual da Paraíba. E-mail: filomena.moita@uol.com.br.

*** Mestre em Educação pela UFPB. Professor da Universidade Federal da Paraíba. E-mail: frazec@uol.com.br.
}

Olhar de professor, Ponta Grossa, 8(2): 77-92, 2005. 
ABSTRACT: This text discusses the connection between the activities of teaching, research and extension as a guiding principle to the quality of higher education. Although we consider the important links that can be established between only two of those activities, we defend a principle which, if put into practice, prevents reductionisms which are verified in the university practice. Guided by that principle, as a doctorate student in Education, we have intervened in a local state school. That intervention is presented in this text as an experience that aimed to link scientific discoveries to the educators' and students' understanding about the articulation of gender relationships, violence and electronic games in school. We supported two central ideas: first, the connection between teaching, research and extension is still not taken into account in the practice of many university professors, either because in graduation the emphasis is on teaching, or becasue in post graduation the emphasis is on research. Secondly, post graduation is an excellent educational level to practice the connection between the three academic activities.

Key words: link between teaching, research and extension, post graduation, higher education

\section{INTRODUÇÃO}

De acordo com a legislação, o tripé formado pelo ensino, pela pesquisa e pela extensão constitui o eixo fundamental da universidade brasileira e não pode ser compartimentado. $\mathrm{O}$ artigo 207 da Constituição de 1988 dispõe que "as universidades gozam de autonomia didático-científica, administrativa e de gestão financeira e patrimonial e obedecerão ao princípio da indissociabilidade entre ensino, pesquisa e extensão".

Dessa forma, ensino, pesquisa e extensão, enquanto funções básicas da Universidade, devem ser equivalentes e merecer igualdade em tratamento por parte das instituições de ensino superior, pois, ao contrário, estarão violando esse preceito constitucional.
Neste texto, temos o propósito de discutir a indissociabilidade das funções desse tripé no qual se assenta o papel da universidade, o que exige, no nível mais abrangente de análise, sempre uma perspectiva ternária, que inclua as três atividades - ensino, pesquisa e extensão - entre as quais, tal como numa "santíssima trindade", há igual importância e íntima unidade. A indissociabilidade é um princípio orientador da qualidade da produção universitária, porque afirma como necessária a tridimensionalidade do fazer universitário autônomo, competente e ético.

Ora, a Universidade tem sido palco de análises e debates que têm dado destaque seja ao ensino, seja à pesquisa, seja ainda à extensão universitária. Assim, se considerados apenas em relações duais, a articulação entre 
o ensino e a extensão aponta para uma formação que se preocupa com os problemas da sociedade contemporânea, mas carece da pesquisa, responsável pela produção do conhecimento científico.

Do mesmo modo, se associados o ensino e a pesquisa, ganha-se terreno em frentes como a tecnologia, por exemplo, mas se incorre no risco de perder-se a compreensão ético-político-social conferida quando se pensa no destinatário final desse saber científico (a sociedade). Por sua vez, quando a (com freqüência esquecida) articulação entre extensão e pesquisa exclui o ensino, perde-se a dimensão formativa que dá sentido à Universidade.

Embora se reconheça a importância dessas articulações duais, o que aqui se defende é um princípio que, se posto em prática, impede os reducionismos que se verificam na prática universitária: ou se enfatiza a produção do novo saber, ou as práticas de intervenção nos processos sociais, ou ainda a transmissão de conhecimentos na formação profissional.

Foi com essa compreensão que, enquanto doutorandos em Educação, matriculados nas disciplinas de "Estágio de Docência I" e "Estágio de Docência II", realizamos um exercício da indissociabilidade entre ensino, pesquisa e extensão. Ele é apresentado neste texto como a experiência de um diálogo interdisciplinar que buscou relacionar o conhecimento científico e o saber de educadores e educandos de uma escola, com vistas à produção de conhecimento acerca da articulação entre relações de gênero, violência e jogos eletrônicos.

Envolvidos nessa experiência, pudemos refletir um pouco acerca das práticas universitárias, muitas delas isoladas ou, no máximo, duais. Defendemos, assim, duas idéias centrais: a primeira delas afirma que a indissociabilidade entre ensino, pesquisa e extensão ainda não é levada em conta na prática de muitos docentes, seja porque na graduação a ênfase é sobre o ensino, seja porque na pós-graduação a ênfase é sobre a pesquisa. A segunda idéia, decorrente da nossa experiência, consiste na afirmação de que o estágio de docência na pósgraduação é uma excelente oportunidade de praticar-se a indissociabilidade defendida. A apresentação de nossa experiência pretende demonstrar esse argumento.

\section{OCONHECIMENTOCIENTÍFICO E INDISSOCIABILIDADE COMO EIXO}

Tratar de indissociabilidade na Universidade é considerar, necessariamente, um debate, por um lado, acerca das relações entre universidade, ensino, pesquisa e extensão. E, por outro lado, confluindo para a formulação de uma tridimensionalidade ideal da educação superior, revela-se outro elemento do debate, aquele das relações entre o conhecimento científico e o conhecimento produzido cul- 
turalmente pelos diferentes grupos que compõem a sociedade em geral. Cumpre, portanto, considerar brevemente esse debate, para melhor entender por que, apesar de ideal, a pretendida indissociabilidade muitas vezes não se verifica na prática universitária.

Como ressalta Silva (2000), as relações entre ensino, pesquisa e extensão decorrem dos conflitos em torno da definição da identidade e do papel da Universidade ao longo da história. Por sua vez, Magnani (2002) indica que, nesses quase duzentos anos de ensino superior no Brasil, pouco a pouco a legislação educacional registrou o esforço por transformar o modelo de transmissão de conhecimento em um modelo de produção e transmissão do saber científico, aliando pesquisa e ensino, como decorrência das pressões por democratização do acesso às universidades. Mais recentemente ainda, a extensão surge como terceiro elemento do fazer acadêmico, resposta às críticas e pressões sofridas pela Universidade, oriundas de setores e demandas sociais (SILVA, 2000). Ensino, pesquisa e extensão aparecem, então, ao final do século XX, como unidos pelo princípio da indissociabilidade, no artigo $207 \mathrm{da}$ Constituição de 2005.

Mal esse princípio foi postulado, porém, já se viu alvo de flexibilizações que denunciam, também no entender de Magnani (2002), tanto a fragilidade da associação entre essas funções, quanto, por trás dessa debilidade, o processo de elitização que atravessa a história da universidade brasileira. "Constata-se a prevalência do caráter elitista presente desde os primórdios da criação do ensino superior brasileiro no século XIX" (MAGNANI, 2002, p.13). Embora legalmente flexibilizado, o princípio termina por ser pouco considerado na prática.

Ora, Castro (2004) mostra que a história da indissociabilidade entre ensino, pesquisa e extensão tem como pano de fundo a história mesma das relações entre conhecimento científico e demandas sociais. Historicamente, o conhecimento científico tornouse uma forma privilegiada de conhecimento, pela grande importância que adquiriu para a vida das sociedades contemporâneas. Segundo Santos (2004, p. 17):

Pode dizer-se que, desde sempre, as formas privilegiadas de conhecimento, quaisquer que elas tenham sido, num dado momento histórico e numa dada sociedade, foram objeto de debate sobre a sua natureza, as suas potencialidades, os seus limites e o seu contributo para o bemestar da sociedade.

Para Pereira Júnior (2005), a pesquisa científica promoveu o florescimento de uma comunidade que - com a implantação tardia das universidades e demais instituições de pesquisa - vem crescendo em três etapas: procurou-se, inicialmente, 
aprender a fazer ciência, não se hesitando em eventualmente "reinventar a roda" como forma de desenvolver uma competência local.

Depois, em uma segunda etapa que se estende até os dias atuais, os cientistas, geralmente já agrupados nas universidades, promoveram a criação e consolidação do sistema de pós-graduação, formando uma nova geração de mestres e doutores para atingir-se, em vários grupos de pesquisa, o nível de excelência científica: revelava-se, assim, a busca de padrões de qualidade e excelência nos trabalhos de pesquisa, com publicações direcionadas para periódicos de primeira linha.

Embora tudo parecesse estar correto, tais padrões foram definidos de modo descontextualizado. Como conseqüência, em sua grande maioria os mencionados trabalhos não estão concatenados com esforços no sentido da promoção do desenvolvimento social, como é o caso brasileiro. $\mathrm{Ou}$ seja, produziu-se um conhecimento desligado das necessidades cotidianas. Segundo Santos (2004, p.40), tal tendência não seria exclusiva da universidade brasileira:

o conhecimento universitário (...) foi, ao longo do Século XX, um conhecimento predominantemente disciplinar, cuja autonomia impôs um processo de produção relativamente descontextualizado em relação às premências do quotidiano das sociedades.
Valendo-se de uma expressão usada pelo mesmo autor, gerou-se um conhecimento para "para inglês ver".

A terceira etapa, que seria a ideal e que se busca atingir, alia à competência científica e tecnológica um vetor pragmático, direcionando as investigações para projetos e parcerias que viabilizem o desenvolvimento. Esse é um aspecto que já vem sendo considerado na aprovação de projetos por algumas agências financiadoras como o CNPq, o que aponta para a emergência do novo modelo. Para Santos (2004, p.29), aconteceu "uma passagem do conhecimento universitário para o conhecimento pluriversitário".

O conhecimento "pluriversitário", nas palavras do autor, distingue-se do conhecimento produzido anteriormente por ser "contextual na medida em que o principio organizador da sua produção é a aplicação que lhe pode ser dada" (SANTOS, 2004, p.30). Como essa aplicação acontece além dos muros universitários, tanto a formulação dos problemas quanto a determinação para resolvê-los e os critérios adotados para o trabalho resultam de "uma partilha entre pesquisadores e utilizadores" (SANTOS, 2004, p.30).

Ainda na opinião de Boaventura de Sousa Santos, o conhecimento característico do séc. XXI "é um conhecimento transdisciplinar que, pela sua própria contextualização, obriga a um diálogo ou confronto com outros tipos de conhecimento" (SAN-

Olhar de professor, Ponta Grossa, 8(2): 77-92, $2005 . \overline{81}$ 
TOS, 2004, p.41).

Ora, a relação com alguns desses outros conhecimentos pode produzirse consideravelmente na atividade de extensão, que se achega ao conhecimento prático, assimilado culturalmente e desenvolvido para responder a demandas da vida cotidiana. Não à toa, segundo autores como Rocha (1986), Fagundes (1986) e Botomé (1992), a preocupação com a extensão universitária nasceu com as universidades populares na Europa, que tinham como objetivo disseminar os conhecimentos técnicos, eminentemente associados a práticas socialmente relevantes. Esse movimento pelas universidades populares, no entanto, foi criticado por Gramsci, que neles apontou a falta de organicidade, seja de pensamento filosófico, seja de solidez organizativa e de centralização cultural (MELO NETO, 2002).

Paulo Freire (1980) trouxe uma reflexão conceitual importante para a extensão, quando publicou o ensaio "Extensão ou Comunicação". Ele defendeu a extensão como uma situação educativa, em que educadores e educandos assumem o papel de sujeitos cognoscentes, mediatizados pelo objeto que desejam (ambos) conhecer. Para Freire, ou se dá um processo de extensão dialógico, ou, então, corre-se o risco de trabalhar com uma interpretação ingênua da realidade, quando não fosse explicitamente um instrumento de dominação, de invasão cultural.

O diálogo, aspecto sobejamente defendido por Paulo Freire, é enfatizado por Boaventura de Souza Santos como principio básico para que a universidade passe a cumprir o seu papel de agência formadora: é ele, portanto, um dos princípios básicos da indissociabilidade.

Conscientes das particularidades que caracterizam cada uma das três funções universitárias, entendemos a indissociabilidade do ensino, pesquisa e extensão como um conhecimento "pluriversitário", que permite, de acordo com as palavras de Santos (2004, p.31), "a inserção da universidade na sociedade e a inserção desta na universidade".

Desse modo, a indissociabilidade pode ser entendida como um princípio orientador da universidade que nasce sob o influxo dos debates que estabelecem o lugar da Universidade no seio da sociedade em geral, recebendo, daí, uma nítida influência daquela terceira tendência sugerida por Pereira Júnior (2005), ou seja, a de um conhecimento científico em diálogo permanente com as demandas sociais. Por isso, apresenta-se também como principio básico em que o diálogo defendido por Freire é potencializado pela revolução das tecnologias, informação e comunicação, permitindo um diálogo que, nas palavras de Santos, substitui a unilateralidade pela interatividade.

A partir desse breve percurso em torno do debate sobre indissociabilidade, por um lado, e as relações entre ciência e realidade social, por outro, 
entende-se melhor agora porque a indissociabilidade ainda não é uma orientação reconhecida sistematicamente por todos na educação superior, mas permanece como um ideal a ser perseguido: o modelo universitário posto em prática por muitas vezes na educação superior ainda é aquele próprio do momento de afirmação e consolidação do saber científico, típico de uma estrutura ainda não eminentemente dialogal (PEREIRA JÚNIOR, 2005).

No caso da pós-graduação, em particular, graças à prerrogativa com que se trata a pesquisa, pode-se também dizer que muitos ainda se encontram na mesma etapa de produção universitária, de sorte que a indissociabilidade ainda é uma meta a ser perseguida. A ênfase, em muitos casos compreensível, atribuída naturalmente à pesquisa deveria realçar, ainda mais, as possibilidades de articulação com o ensino e a extensão, e não contribuir para a dissociação entre os fazeres que constitucionalmente fixam a identidade da Universidade no Brasil.

Em decorrência disso, a extensão termina por ser relegada a um lugar secundário na pós-graduação, contribuindo para práticas de pesquisa e ensino dissociadas da realidade. Ora, na verdade, a extensão apresenta-se como uma estrada de mão dupla (MELONETO, 2003), pela qual há uma troca entre os conhecimentos universitários e os comunitários, diante das reais necessidades, anseios e aspirações sociais, intercâmbio em que a
Universidade é positivamente provocada, influenciada e fortalecida. Como afirma Castro (2004, p.14), a extensão

se coloca como um espaço estratégico para promover práticas integradas entre as várias áreas do conhecimento. Para isso é necessário criar mecanismos que favoreçam a aproximação de diferentes sujeitos, favorecendo a multidisciplinaridade; potencializa, através do contato de vários individuos, o desenvolvimento de uma consciência cidadã e humana, e assim a formação de sujeitos de mudança, capazes de se colocarem no mundo com uma postura mais ativa e crítica. A extensão trabalha no sentido de transformação social.

Desconsiderar a extensão - excluindo-a das atividades de ensino e pesquisa na pós-graduação - é não só promover a dissociação que fere a indissociabilidade e reproduz um velho modelo acadêmico, como perder um vasto e indispensável terreno de descobertas e aprendizagens que, acima de tudo, situa as ciências no seu justo lugar de saberes a serviço do ser humano, histórica e socialmente compreendido. Menosprezar a extensão ou reduzi-la ao ensino e à pesquisa (SILVA, 2000) é também negar as várias contradições que atravessam o interior da Universidade, desde suas origens até as transformações recentes.

O melhor é que, mesmo num con-

$$
\text { Olhar de professor, Ponta Grossa, 8(2): 77-92, } 2005 . \overline{83}
$$


texto universitário ainda não totalmente "pluriversitário", é possível exercitar-se a indissociabilidade. $\mathrm{O}$ estágio de docência parece-nos ocasião propícia para isso, pois conduz o pós-graduando para um momento em que o ensino abre portas para o contato com o conhecimento dos educandos, numa situação que pode perfeitamente extrapolar os muros adêmicos, sem que se perca a dimensão investigativa que norteia a pesquisa. É o que pretendemos demonstrar, com o caso de nossa experiência no estágio de docência, a seguir apresentada.

2.UMAEXPERIÊNCIAQUEAPONTA PARA A INDISSOCIABILIDADE: OESTÁGIO DOCENTE DE PÓS-GRADUANDOS NUMAESCOLAMUNICIPAL

É Castro (2004, p.14) quem afirma: "no caso da extensão, o que percebemos é que ela produz conhecimento a partir da experiência e assim tem uma capacidade de narrar sobre o seu fazer". Narrar uma experiência implica pensá-la. Considerando que nossa reflexão fundamenta-se sobre essa experiência, cumpre relatá-la sumariamente, a fim de que seja possível compreender-se o cenário e o processo sobre os quais se situa nossa discussão.

Por dois semestres letivos, na condição de alunos do doutorado em Educação, realizamos estágio de docência em uma escola pública na capital de nosso Estado, procurando exercitar nessa intervenção o princípio da indissociabilidade entre ensino, pesquisa e extensão.

A escola que se constituiu em lugar de nosso trabalho é pública, municipal, e serve a uma comunidade de baixa renda da periferia da capital. Em 2004, contava com uma equipe composta por diretora, vice-diretora, dez professores pela manhã, doze à tarde e dez à noite, atendendo a 1070 alunos, distribuídos desde a Alfabetização à $8^{\mathrm{a}}$ série, além de uma turma de Aceleração e de Educação de Jovens e Adultos (ciclos 1 e 2), à noite.

A unidade de ensino, enquanto lá estivemos, não tinha profissionais da educação exercendo funções técnicas (supervisão, orientação, psicologia educacional-escolar ou serviço social). O professorado, majoritariamente composto de prestadores de serviço, participou dos encontros de formação continuada, promovidos pela Secretaria Municipal de Educação até o ano de 2004.

Já o alunado é proveniente, na sua maioria, do próprio bairro e dos bairros circunvizinhos: por conta desse grupo, segundo a avaliação da direção, a escola tem como maiores problemas a violência vivida pelo alunado e por ele reproduzida no interior da unidade de ensino, as questões relativas à aprendizagem de valores e condutas sobre a sexualidade e a falta de requisitos do alunado para a aprendizagem (o que é considerado uma dificuldade em acréscimo para o 
ensino).

Nosso trabalho teve a duração de dez meses, no período compreendido entre maio de 2004 e março de 2005. Em 2004, iniciamos o trabalho por considerar as possibilidades de articulação entre os conhecimentos sobre relações de gênero, jogos eletrônicos e violência na escola. Nosso objetivo, então, foi gerar, teórica e praticamente, conhecimentos sobre aquelas articulações possíveis que pudessem ser incorporados ao desenvolvimento curricular e às aprendizagens individuais do professorado e do alunado. Ora, pretendíamos cumprir tal meta através da realização de três oficinas pedagógicas - duas com o professorado e uma com o alunado - que versassem sobre as articulações temáticas pretendidas.

Assim, em maio de 2004, a partir do conhecimento de uma demanda de assessoria que a própria escola havia feito à universidade, preparamos um projeto de extensão que, propondo uma articulação entre nossas investigações doutorais e aquela de nossa orientadora, se constituía de três dimensões: a pesquisa, com que começaríamos nossa intervenção, a fim de sabermos o que pensavam professorado e alunado acerca da temática que propúnhamos; o ensino, em torno do qual se organizariam as oficinas pedagógicas (como uma das atividades concernentes à primeira parte de nos- so estágio de docência doutoral); e a extensão, caracterizada não apenas pela natureza extramuros universitários da atividade, mas pela proposta de prestação de um serviço de utilidade para aquela escola e, a partir dela, para o professorado, o alunado e a comunidade de inserção.

Buscávamos, acima de tudo, o diálogo com aqueles alunos e professores, de modo a fazê-los mais participantes de seu cotidiano. Mais que levar idéias prontas, queríamos saber o que eles e elas, como atores de seu cotidiano, tinham a nos falar e o que poderíamos juntos construir, através do momento de oficinas pedagógicas.

A pesquisa foi, então, o ponto de partida da extensão. A partir da construção e aplicação de dois questionários (um para o professorado e outro para o alunado), coletamos dados que nos subsidiaram no planejamento das oficinas. Conforme mostramos em trabalhos anteriores, os dados obtidos mostraram-nos que, no tocante às temáticas de nossos interesses, apenas a da violência era percebida pelo professorado como um problema presente na escola, demandando soluções para o que seria uma banalização das situações de violência interpessoal consideradas menos graves ${ }^{1}$. As causas apresentadas para a violência na escola revelaram hipóteses sócioambientais implícitas, particularmen-

\footnotetext{
${ }^{1}$ Particularmente as agressões morais, verbais, sobre as quais escreveram os próprios professores: "é normal", "tem em qualquer escola", "sem conseqüência grave".
} 
te de caráter psicológico ${ }^{2}$. Somada a tudo isso, a referência à televisão complementa o cenário em que, em grau crescente de abrangência, os âmbitos familiar, comunitário e midiático aparecem como articulados numa teoria sobre a cultura de violência.

Nessa articulação a escola não se encontra, por não ser reconhecida como produtora de violências: ou porque os ideais pedagógicos são avessos à violência, ou porque a geração de violência é concebida apenas fora da escola. A escola, assim, torna-se palco de reprodução de violências, não de sua produção 3/4 esquecendo-se os docentes de que, com suas especificidades, a escola também participa ativamente dos processos de violência, seja para fomentá-los, seja para preveni-los (ORTEGA\& DELREY, 2002).

A temática dos jogos eletrônicos, por sua vez, não era percebida pelo professorado como relevante para a escola. Entretanto, as respostas do alunado ao questionário a ele destinado não só afirmaram a importância dessa temática - atravessada que está pela discussão em torno da sexualidade e das relações de gênero - , mas apontaram para o fato de que, através do jogo, são reproduzidas relações de poder entre homens e mulheres, por meio de um padrão social de inclusão / exclusão, apontado por Elias e Scotson (2000). Ao analisar as respostas dos alunos da escola para a pergunta "quem joga mais meninos ou meninas", constatamos que, no que tange aos jogos eletrônicos, eles são uma prática que, tal qual a violência, reafirma, dentro e fora da escola, relações desiguais, cabendo à escola a tarefa de questionar os valores reproduzidos pelas práticas dos jogos e da violência.

Ora, foi exatamente para pôr em questão essas relações, reconhecidas ou não pela escola, que promovemos

\footnotetext{
${ }^{2}$ A família e a exposição a mídias violentas são atribuídas como responsáveis pela conduta violenta do alunado Este último aspecto explicativo permite pensar na relação entre escola e comunidade. O bairro em que se situa a escola é vista como perigoso, graças à ação de gangues organizadas em torno do tráfico de entorpecentes. Desse modo, o ambiente é hostil e, nele, as famílias são representadas também como violentas.

${ }^{3}$ Algumas das respostas do alunado são bem ilustrativas: "Eu acho quem joga mais são os meninos", "tem menina que joga no shopping, mas elas são sapato", "Eles sabem mais que as meninas", "só vejo meninos jogando no playstation". Os meninos, como grupo estabelecido, intitulavam-se os melhores jogadores, como os que sabem, defendem aquele espaço como só deles. As meninas eram constituídas pelo grupo novo que estava entrando naquele espaço, constituindo-se assim em ameaça ao poder dos já estabelecidos. Considerados como "melhores", os meninos sentem-se dotados de uma espécie de virtude que é compartilhada pelos membros de seu grupo e que falta aos outros (no caso, às meninas). Por outro lado, as meninas afirmam que "a mãe não deixa", ali é um espaço "só para homem, porque menina não é para jogar". As meninas menosprezam-se, considerando-se com menos habilidade para jogar.
} 
as oficinas pedagógicas em 2004. Planejadas a partir dos resultados obtidos com a pesquisa, durante os meses de maio a julho, e executadas entre 12 e 14 de julho, as oficinas inspiraram-se no tema das Olimpíadas (que estavam para ocorrer, à época) e desenvolveram o lema "Eles, Elas: Elos na Escola", a fim de articular ("elos") a temática das relações de gênero ("eles, elas"), detectada na pesquisa, com o universo escolar ("na escola").

Tais oficinas tiveram um caráter nitidamente associado às atividades de ensino, momento em que pretendemos, na condição de estagiários em docência, apresentar sob nova roupagem facetas não exploradas (como era o caso dos jogos) ou banalizadas (como era o caso da violência) do cotidiano do alunado, demonstrando, sobretudo para o professorado, ser possível incorporá-las nas atividades de ensino promovidas na escola, através de temas transversais (como os da ética e da orientação sexual, por exemplo). Pretendemos, portanto, contribuir com a formação continuada dos educadores daquela escola.

O planejamento, a execução e o material produzido pelo professorado e pelo alunado durante as oficinas, assim como dois jogos eletrônicos idealizados especialmente para o uso na escola foram, entre agosto e novembro de 2004, compilados em um CD-ROM por nós produzido como resultado desse trabalho: oferecido à escola e a algumas outras unidades da rede municipal de ensino em no- vembro de 2004, como forma de multiplicação das aprendizagens lá realizadas, ele visou também intervir no cotidiano da escola atendida, assumindo, assim, o caráter de recurso didático. Completou-se, desse modo, o caráter dialogal próprio à extensão, entendida como "um trabalho social, ou seja, ação deliberada que se constitui a partir da realidade e sobre esta realidade objetiva, produzindo conhecimentos que visam à transformação social" (MELO NETO, 2003, p.15).

Após uma visita de avaliação dos trabalhos, em dezembro de 2004, percebemos, em janeiro de 2005, a possibilidade de continuarmos nosso estágio de docência na mesma escola, graças ao convite que nos foi feito pela direção para participarmos do momento de planejamento escolar, no início de fevereiro. O pedido inicial ("ajuda no planejamento") convidounos a nova pesquisa, a fim de sabermos, desta feita, quais as demandas próprias àquele momento do ano letivo e em que medida poderíamos ajudar o professorado a lidar com elas.

Elaboramos um questionário que buscava entender a experiência pessoal do professorado em relação à sua carreira, aprofundar nossos conhecimentos sobre o professorado daquela escola (no que dissesse respeito às nossas investigações doutorais) e, mais especificamente, as demandas de assessoria para o planejamento.

Destacamos aqui apenas os dados mais relevantes dessa segunda pesquisa: considerando que o qua- 
dro docente participante das pesquisas foi majoritariamente mantido, houve a possibilidade de articulação entre a pesquisa de 2004 e a de 2005 . Uma quase total ausência de contato com computadores, Internet ou jogos eletrônicos ajuda a entender por que não tinha o professorado estabelecido qualquer relação entre os jogos e a vida na escola. Além disso, as reações que o professorado afirma experimentar diante da violência na escola (tristeza, sobretudo, e calma como condição para a intervenção com vistas à solução do conflito pelo diálogo, a conversa entre agressor/a e agredido/a) são melhor compreendidas quando se reconhece que elas indicam ser a agressão moral o tipo de violência mais significativamente provocador de reação do professorado, não só por ser percebido como o mais freqüente, mas por não implicar, necessariamente, riscos à vida nem recurso à força física.

Ainda, as dificuldades apontadas quando da realização do planejamento indicam, em particular, problemas em executar o planejado $(46,7 \%)$, por razões que as outras variáveis apontadas pelo professorado - carência de material e de livros, dificuldades em gerenciar a relação entre plano e tempo de sua execução, distância entre os planos escolares e a vida do alunado (o que acarretaria uma baixa mo-tivação deste último) - ajudam a esclarecer.

As demandas do professorado revelaram, por fim, a necessidade de um aprofundamento docente no que se refere ao uso de jogos, de dinâmicas e de atividades lúdicas para a apresentação de conteúdos formais e de temáticas transversais na escola, associada à demanda por material didático.

Como tínhamos sido chamados para ajudar no planejamento, foram as demandas relativas a esse momento, mais especificamente, que determinaram os rumos da etapa dedicada ao ensino, nas atividades de extensão em 2005: a partir delas, foi planejada e organizada uma oficina pedagógica, intitulada "Vivendo e aprendendo". Essa oficina enfocou a temática da formação ética na escola, através de três dinâmicas de grupo, escolhidas por serem também utilizáveis em sala de aula pelo professorado participante. Realizada em 22 de fevereiro do corrente, a oficina proporcionou às participantes (apenas mulheres, desta feita) descobertas em relação à semelhança entre suas condutas nas dinâmicas e as condutas do alunado sob seus cuidados, bem como a discussão acerca da possibilidade de aplicar as temáticas transversais aos conteúdos curriculares - incluindo aí as experiências e as práticas do alunado ${ }^{4}$.

${ }^{4} \mathrm{O}$ feedback apresentado por algumas delas dá conta desse efeito: "Adorei as experiências (dinâmicas) trabalhadas neste encontro, pois beneficiam todos os conteúdos de sala de aula". "Foi muito importante e apresentável para nossos conteúdos serem aplicados". "Amei, foi de acordo com nossa necessidade!" "Eu adorei essa oficina e realmente aproveitarei tudo o que eu aprendi hoje. Obrigada!"

88 Olhar de professor, Ponta Grossa, 8(2): 77-92, 2005. 
Entendemos que a Oficina realizada em 2005 também pode ser caracterizada como um projeto realizado no interior dessa atividade de assessoria que, articulando ensino, pesquisa e extensão, atendeu, no que tange ao ensino, à necessidade de treinamento das professoras e ao cumprimento das atividades concernentes a nosso estágio de docência. É essa articulação entre ensino, pesquisa e extensão que entendemos ser possível e necessária, pois, mais uma vez buscando pôr em prática o princípio da imbricação entre ensino, pesquisa e extensão universitários, aproxima-se um pouco mais da realidade local vivida pelos educadores e educadoras da rede pública de ensino fundamental - caracterizada por lacunas e por problemas, mas também por sucessos e realizações em meio a condições materiais e pedagógicas adversas.

3. A INDISSOCIABILIDADE NA PÓS-GRADUAÇÃO NÃO É SÓ POSSÍVEL: É NECESSÁRIA(CONCLUINDO)

Por mais proclamado que seja, o princípio da indissociabilidade entre pesquisa, extensão e ensino termina por ser esquecido na prática universitária, tal como ocorre na pós-graduação. É freqüente que os pósgraduandos sejam encontrados apenas nas salas de aula da graduação (no caso dos mestrandos) e da pósgraduação (no caso dos doutorandos), esquecendo-se de que, além das salas de aula universitárias, é possível - e necessário - também encontrar campo de estágio docente fora dos muros acadêmicos.

Essa prática, que continua a reproduzir-se, está estruturada sobre uma clara hierarquia: se a graduação tornou-se o lugar do ensino, a pósgraduação tornou-se o da pesquisa, sendo que tanto a extensão enquanto o ensino são considerados tarefa inferior à pesquisa. Na pós-graduação a extensão é relegada, como se não pertencesse àquela indissociável articulação sobre que se fundamenta a universidade brasileira. Corrobora essa análise a posição de Valêncio (1999, p.75), que afirma: "Os 'competentes' em pesquisa e pós-graduação proclamam-se superiores aos que se dedicam ao ensino de graduação e abandonam esta atividade para disporem de mais tempo para a produção científica", de modo que se criam "desprezos de mão dupla" (VALÊNCIO, 1999, p.75), a distanciarem ensino de pesquisa, pesquisa de extensão, extensão de ensino, numa prática que contraria o princípio da indissociabilidade.

Ora, a mesma autora indica que as tensões internas à universidade remetem à questão da legitimação da educação superior no diálogo com a sociedade de que (e para que) surge a academia. No que tange à extensão, em particular, a indissociabilidade oferece à formação discente um espaço capaz de "permitir a atualização dos conteúdos programáticos e, simulta- 
neamente, embasar os novos profissionais numa ética de cidadania" (VALÊNCIO, 1999, p.79). Pesquisa, ensino e extensão articulam-se, destarte, na formação acadêmica, de modo a promoverem uma consciência profissional eticamente fundamentada e empiricamente atualizada.

Esse ideal apontado pela autora é capaz de reverter o quadro real de apartação entre ensino, pesquisa e extensão? Acreditamos que sim, se for tomado conscientemente como eixo orientador dos trabalhos universitários. Em nosso caso, enquanto pósgraduandos, acreditamos que uma oportunidade particularmente fecunda para o exercício da indissociabilidade consiste no estágio de docência.

O estágio de docência por nós antes descrito pode servir como bom exemplo para tanto: realizado fora dos muros universitários, buscando "uma reelaboração compartilhada do mundo aspirado, refletivo e vivido" (VALÊNCIO, 1999, p.79) na relação entre universidade e sociedade, nosso estágio conduziu-nos à pesquisa, ao ensino e à extensão articuladamente, numa partilha de saberes entre pesquisadores e utilizadores (SANTOS, 2004).

Como pretendemos mostrar, a assessoria desenvolvida junto à escola referida demandou de nós a pesquisa - para que conhecêssemos a realidade com que trabalharíamos: a pesquisa pode ser considerada, assim, usando ainda a imagem de Valêncio (1999), como a voz desse "outro" constituí- do pela realidade social. Se não levássemos em conta essa voz, nada teríamos a dizer que pudesse ser efetivamente assimilável pelo professorado e pelo alunado da escola. E mais: a pesquisa gerou publicações, que socializaram alguns dos conhecimentos produzidos na experiência.

Demandou, também, o ensino posto que tínhamos algo a falar para esse "outro". Nossa intervenção docente, nesse sentido, buscou ressaltar certos valores tacitamente presentes nas práticas docentes e discentes: por que os jogos não fariam parte da vida da escola, se os alunos e as alunas (aqueles bem mais que estas) jogam? Como o professorado poderia tratar da violência na escola sem incluir-se como possível agente legitimador de violência, reproduzindo, inconscientemente, estereótipos opressivos, como os de gênero? Buscou, igualmente, fornecer material e experiência para os /as docentes aprenderem a como ensinar melhor. Como manter motivado o alunado para a aprendizagem dos conteúdos, quando falta a formação docente acerca de métodos para diversificar o ensino?

Assim, o ensino consistiu de ocasiões para a reflexão e a (re)construção de conceitos e valores em que estavam mergulhados o alunado e o professorado, mas também da aprendizagem de técnicas pedagógicas capazes de tornar a aprendizagem dos conteúdos mais prazerosa.

A assessoria requereu de nós, ainda mais, sermos capazes de conceber, 
organizar e executar projetos de extensão que atendessem, pontual e localmente, a certas demandas de formação do professorado e de reflexão do alunado. Diferentemente dos "ressentimentos de mão dupla", a extensão apareceu, nesse contexto, tanto como uma decorrência natural do ensino e da pesquisa, quanto como uma fonte para ambos (já que, sem as demandas da escola não haveria pesquisa nem ensino, em nosso caso).

Daí afirmarmos a necessidade da indissociabilidade na pós-graduação. A extensão e o ensino não são "acessórios" à pesquisa, mas continuações naturais desta, se a produção científica do conhecimento quiser ser efetiva, quiser intervir para modificar a realidade estudada - voltando a enriquecer-se, nesse processo, por dela alimentar-se perpetuamente. Donde que, sem a indissociabilidade, não há sobrevivência da pesquisa.

O ensino na pós-graduação também se alimenta da extensão e a ela serve. Cremos ser nossa experiência também uma prova disso, pois, enquanto pós-graduandos extensionistas, tínhamos um certo conhecimento a oferecer - particularmente aquele produzido em torno das relações de gênero, da violência na escola, dos jogos eletrônicos e do recurso a dinâmicas de grupo para o ensino de temáticas transversais. Mas tal conhecimento só se efetivou quando foi posto à prova da avaliação daquelas que iriam utilizá-lo, se parecesse eficaz - o professorado da escola, em nossa experiência.

O estágio de docência parece-nos, por conseguinte, uma rica (e ainda não suficientemente explorada) oportunidade para o exercício da indissociabilidade das atividades acadêmicas na pós-graduação.

\section{REFERÊNCIAS}

BOTOMÉ, S. P. Extensão universitária no Brasil: a administração de um equívoco. São Carlos, 1992.

CASTRO, L. M. C. A universidade, a extensão universitária e a produção de conhecimentos emancipadores. In: ASSOCIAÇÃO NACIONAL DE PESQUISA EM EDUCAÇÃO. Caxambu, MG. Anais da $27^{\text {a }}$ Reunião. 2004. Disponível em: < http://www2.uerj.br/ anped11/> Acesso em 12/04/05.

ELIAS, N; SCOTSON, J. Os estabelecidos e os outsiders: sociologia das relações de poder a partir de uma pequena comunidade. Rio de Janeiro: Jorge Zahar Editor, 2000.

FAGUNDES, J. Universidade e compromisso social: extensão, limites e perspectivas. Campinas: Editora Unicamp, 1986.

FREIRE, P. Extensão ou comunicação? 5. ed. Rio de Janeiro: Paz e Terra, 1980.

MAGNANI, I. Ensino, pesquisa, extensão e a nova tipologia do ensino superior brasileiro. In: REUNIÃO ANUAL DA ANPED, 25., 2002, Caxambu, MG. Anais eletrônicos... Caxambu, MG, 2002. Disponível em: < http://www2.uerj.br/ $\sim$ anped11/> Acesso em 12/abr. 2005.

MELO NETO, J. F. Extensão Universi- 
tária: bases ontológicas. João Pessoa: Editora Universitária, 2002.

Extensão universitária e produção do conhecimento. Conceitos. Revista da ADUF/PB, n. 09, pp.13-17, jan-jun, 2003.

ORTEGA, R; DEL REY, R. Estratégias educativas para a prevenção da violência. Brasília: UNESCO, UCB, 2002.

PEREIRA JÙNIOR, A. A universidade pública e os desafios do desenvolvimento. São Paulo: La Insígnia, 2005.

ROCHA, R. M. G. Extensão universitária: extensão ou domesticação? São Paulo: Cortez, 1986.

SANTOS, B. S. A universidade no século XXI. São Paulo: Cortez, 2004.

SILVA, M. G. Universidade e Sociedade: cenário da extensão universitária?. In: ASSOCIAÇÃO NACIONAL DE PESQUISA EM EDUCAÇÃO. Caxambu, MG. Anais da 23 ${ }^{\text {a }}$ Reunião. 2000. Disponível em: < http://www2.uerj.br/ anped11/> Acesso em 12/04/05.

VALÊNCIO, N. F. L. S. A indissociabilidade entre Ensino/ Pesquisa/ Extensão: verdades e mentiras sobre o pensar e o fazer da Universidade Pública no Brasil. Proposta.n. 83, p.72-81, dez. 1999/fev. 2000. Disponível em: < www.fase.org.br/proposta/83/72-82.pdf > Acesso em 12 abr. 2005.

Encaminhado em: 07/10/05

Aceito em: 06/11/05 